\title{
Intraoperative Finding of Cholesteatoma in Central Tympanic Perforation
}

\author{
María Luisa Navarrete Álvaro*, María Teresa Burgos Ortega, Jose Salazar Clavijo and María Labeaga \\ Sánchez
}

Otorhinolaryngology and Head \& Neck Surgery Department, Vall d'Hebron Universitary Hospital, Barcelona, Spain

*Corresponding author: María Luisa Navarrete Álvaro, Otorhinolaryngology and Head \& Neck Surgery Department, Vall d'Hebron Universitary Hospital, Barcelona, Spain.
Received Date: June 22, 2020

Published Date: July 08, 2020

\section{Introduction}

Clinically, the chronic otitis media is defined as the recurrent or chronic infection of the middle ear of a patient with an eardrum perforation, and it can be classified as:

1) Benign (or inactive), which is characterized by a dry tympanic perforation, which is not related to an active infection.

2) The chronic effusive otitis media (also known as serous chronic otitis media), which presents a continuous serous drainage, without pathogen grown.

3) The chronic suppurative otitis media, which is diagnosed when there is persistent purulent drainage through the tympanic perforation.

On the other hand, when we talk about the chronic cholesteatomatous otitis media, we refer to the accumulation of desquamative keratinized epithelium, either in the tympanic cavity or in the mastoid bone, which may be secondary to an eardrum perforation but may also occur as a primary lesion [1]. Marginal perforations are considered to be more dangerous because they are usually associated with the development of a cholesteatoma [2]. In this type of perforations, the stratified squamous epithelium of the external auditory canal can grow into the middle ear and form a cholesteatoma [3].

On the contrary, central perforations have been considered as innocuous since cholesteatoma is not usually associated with them. These may be anterior, posterior, inferior or subtotal; dry or active, which can cause recurrent otorrhoea. When inflammatory pathology associated with central perforations is found, it implies the formation of granulation tissue and polyps in addition to the fixation or destruction of the ossicular chain. Despite the fact that this type of perforations is not usually related to the formation of cholesteatoma, cases have been reported in the literature, although the prevalence is very low [4]. In this review we want to explain three cases in which cholesteatoma was found as a casual discovery, in patients with central perforation, as opposed to what is commonly described in the bibliography.

\section{Clinical Cases}

\section{Case 1}

26-years-old male patient with no medical history of interest, who suffered burns due to fulguration from a lightning stroke, with an estimated total extension of $2,5 \%$ of the total body surface with burns and polytrauma associated with loss of consciousness. During the hospital admission he did not show signs of neurologic focality but he did mention bilateral hearing loss with left side predominance, denying vertiginous syndrome or another otorhinolaryngologic symptoms. The cranial CT informed us about a left parietal subarachnoid haemorrhage, a comminute fracture of the right zygomatic arch with no occupation of tympanic cavity nor the mastoid bone (Figure 1,2).

In the otorhinolaryngology evaluation seen under microotoscopic vision of both ears, we appreciated the external auditory canal with hematic rests, very erythematous and thickened eardrum with pulsatile otorrhoea of both ears; topical antibiotic 
treatment was indicated. In the audiometry we found a mild bilateral transmission hearing loss and the tympanography showed flat curves. In the follow up (15 days later) we find a dry central perforation in the right ear and dry subtotal perforation in the left ear; 6 months later we recommended bilateral myringoplasty, starting with the right ear which presented more hearing loss. When the edges of central perforation were revived, a pearl suggestive of cholesteatoma was observed and extracted, desisting from the tympanic plasty. Central perforation cholesteatoma was confirmed in the histopathologic study.

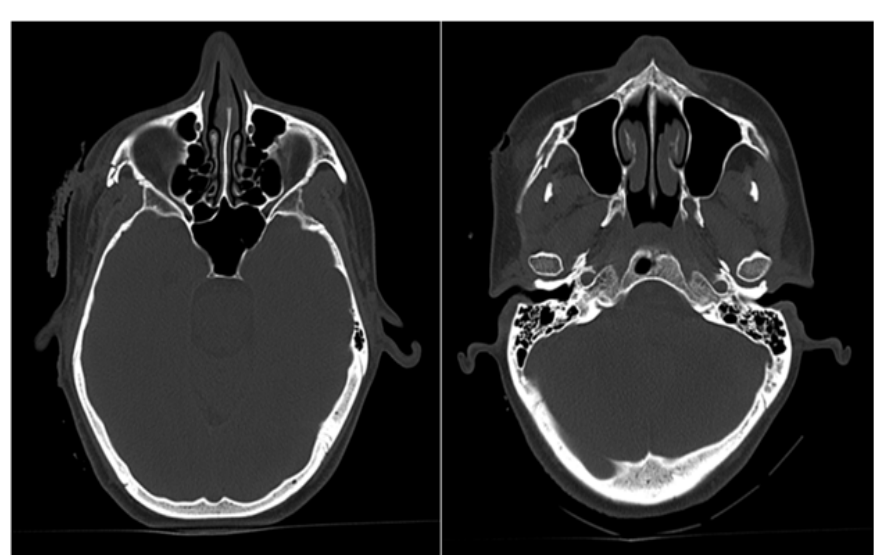

Figure 1,2: Bone window constrast CT which shows comminute fracture of the right zygomatic arch, with no occupation of the tympanic cavity, neither the mastoid bone

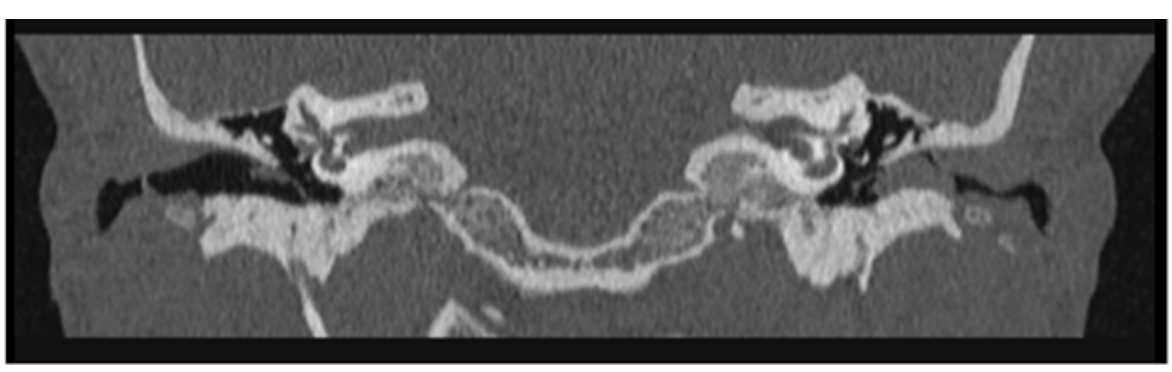

Figure 3: Coronal cut of the CT's petrous bone with no occupation of the average inner ear.

\section{Case 2}

38-years-old female patient with asthma and allergic rhinitis, was referred to our centre presenting a tympanic perforation of the right ear of long-data, not associated to episodes of otorrhoea. The otoendoscopic exploration showed a normal left ear and a dry central perforation of the right eardrum. Surgical treatment was indicated to accomplish the closure of the perforation. An attic occupied by cholesteatomatous-looking tissue, that was not present in the previous explorations nor radiologic studies (Figure 3), was evident during this surgical procedure and the histophatological study confirmed the diagnosis of cholesteatoma. After 18 months of clinical and radiological follow up, findings compatible with granulomatous tissue were shown in the middle ear and surgical treatment was decided. Right aticoantrostomy is performed and now the patient has been free of disease for two years.

\section{Case 3}

42-years-old male patient with no medical history, who comes to our center referring intermittent otorrhoea in the left ear and ipsilateral hearing loss. A dry central eardrum perforation was revealed in the micro-otoscopy and a myringoplasty is suggested. In this surgical act, epidermic tissue with inflammatory signs in the attic was observed and just like in the other cases, this findings were not shown in the previous follow ups not CT scan (Figure 4). The histopathological study resulted in cholesteatoma and currently the patient follows control without signs of recurrence.

\section{Discussion}

It has been widely described that central perforations tend to have fewer complications in comparison with the marginal ones. However, both sequelae and complications have been reported, albeit to a lesser extent [5]. It is accepted that histologically the inflammation of the middle ear affects the inner mucous layer of the tympanic membrane in some of these perforations, allowing the external keratinized epithelium to migrate to the inside of the tympanic cavity generating a cholesteatoma. Cholesteatoma has been defined as a mass of stratified squamous tissue found with the temporal bone and its epithelium is characterized by a dysregulation of the keratinocytes [6]. The microscopic study of the basement membrane shows a layer of extracellular matrix separating the epithelium from the connective tissue [7]. Although we have previously mentioned the low incidence of cholesteatomas in central perforations, authors as Matsui, K \& Kubota [9] and collaborators published a review showing central perforations in 8 
of 142 middle ears with acquired secondary cholesteatoma $(5,6 \%)$ $[8,9]$. There were no signs of cholesteatomatous otitis media in clinical and complementary exploration in our three patients, but it was in the surgical act when the presence of cholesteatoma was observed.

Despite the etiologic difference between our patients, publications like the one of Ruedi et at, explain that the inflammation and the toxic effects of the exudate may cause injury to the mucous epithelium and affect its basement membrane. These changes added to poor ventilation of the middle ear could support the growth of papillary squamous epithelium there $[10,11]$. We want to add a study in which central eardrum perforation observed in 29 temporal bones of 25 patients of the same age were included. The authors Oktay [12] showed that central eardrum perforations whether caused by inflammatory pathology or by the placement of ventilation tubes, should not be considered as mere defects: $62 \%$ of the tympanic membrane with central perforations showed excessive eardrum thickening, 66\% showed signs of sequelae or tympanosclerosis with papillary projections and epithelial infiltration towards the middle ear [12,13].

\section{Conclusion}

Cases of chronic otitis media associated to secondary cholesteatoma with central perforation are uncommon; however, it is a finding reported in the literature and should be taken into consideration. When doing a myringoplasty, it is imperative to start by examining the tympanic cavity thoroughly, taking samples of those tissues that may make us suspect of a cholesteatomatous lesion. Its diagnosis will be essential to properly guide the treatment. In addition, adequate follow-up of the patient for the assessment of possible recurrences should be carried out.

\section{Acknowledgement}

None.

\section{Conflict of Interest}

The authors state that there is no conflict of interest.

\section{References}

1. Lusting MD, Limb MD (2018) Chronic otitis media, cholesteatoma and mastoiditis in adults. Post TW (edt.), Waltham MA: UpToDate Inc.

2. Mills RP (1997) Management of CSOM, Scott-Brown's Otolaryngology, ( $6^{\text {th }}$ edn.) Oxford: Reed Educational and Professional Publishing Ltd, UK.

3. Dhingra PL (2004) Disease of Ear Nose and Throat. ( $3^{\text {rd }}$ edn.), Amsterdam: Elsevier p: 91.

4. Kingsnorth A, Bowley D (eds.) (2011) Fundamentals of head and neck surgery. In: Fundamentals of Surgical Practice ( $3^{\text {rd }}$ edn.), pp: 308, Newyork: Cambridge University Press, USA.

5. Yamashita T (1985) Histology of the tympanic membrane perforation and the replacement membrane. Acta Otolaryngol 100: 66-71.

6. M Bernal Sprekelsen, A Anonopoulos, G Borkowski, H Sudhoff (2001) Alterations of the basement membrane in the cholesteatoma of the middle ear. Acta Otorrinolaringol Esp 52: 330-335.

7. Grinnell F (1984) Fibronectin and wound healing. J Cell Biochem 26: 107-116.

8. Isaacson G (2007) Diagnosis of pediatric cholesteatoma. Pediatrics 120: 603-608.

9. Matsui K, Kubota T, Takemura H, Nagase D, Hayashi Y (2001) Study of cholesteatomas with central perforation of the ear drum-A new theory of secondary acquired cholesteatoma. Oto-Rhino-Laryngology Tokyo 44: 345-350.

10. Palva T, Johnsson LG (1984) Finding in a pair of temporal bones from a patient with secretory otitis media and chronic middle ear infection. Acta Otolaryngol 98: 208-220.

11. Ruedi L (1979) Pathogenesis and surgical treatment of the middle ear cholesteatoma. Acta Otolaryngol Suppl 361: 1-45.

12. MF Oktay (2005) American Journal of Otolaryngology. Head and Neck Medicine and Surgery 26: 393-397.

13. Rutkowska J, Özgirgin N, Olszewska E (2017) Cholesteatoma Definition and Classification: A Literature Review. J Int Adv Otol 13: 266-271. 